\title{
DESIGN AND IMPLEMENTATION OF 4T, 3T AND 3T1D DRAM CELL DESIGN ON 32 NM TECHNOLOGY
}

\author{
Prateek Asthana and Sangeeta Mangesh \\ Department of Electronics and Communication \\ JSS Academy of Technical Education, Noida
}

\begin{abstract}
In this paper average power consumption, write access time, read access time and retention time of dram cell designs have been analyzed for the nano-meter scale memories. Many modern day processors use dram cell for on chip data and program memory storage. The major power in dram is the off state leakage current. Improving on the power efficiency of a dram cell is critical for the improvement in average power consumption of the overall system. $3 T$ dram cell, $4 T$ dram and 3T1D DRAM cells are designed with the schematic design technique and their average power consumption are compared using TANNER EDA tool average power consumption, write access time, read access time and retention time of $4 T, 3 T$ dram and $3 T 1 D$ DRAM cell are simulated and compared on $32 \mathrm{~nm}$ technology.
\end{abstract}

\section{KEYWORDS}

Low Power, DRAM, 3TDRAM, 4TDRAM, 3T1D DRAM

\section{INTRODUCTION}

Memories play an essential role in design of any electronics design where storage of data is required. Memories are used to store data and retrieve data when required. Read Only Memory (ROM) and Random Access Memory (RAM) are two types of memories used in modern day architectures. Random Access Memory is of two types Dynamic Random Access Memory (DRAM) and Static Random Access Memory (SRAM). SRAM is static in nature and faster as compared to DRAM.SRAM is expensive and consume less power. SRAM have more transistors per bit of memory. They are mostly used as cache memories. DRAMS on the other hand are dynamic in nature and slower as compared to SRAM. DRAM are expensive and consume more power, they require less transistor per bit of memory. They are mostly used as main memories. DRAM is widely used for main memories in personal and mainframe computers and engineering workstation. DRAM memory cell is used for read and write operation for single bit storage for circuits. A single DRAM cell is capable of storing 1 bit data in the capacitor in the form of charge. Charge of the capacitor decreases with time .Hence refresh signals are used to refresh the data in the capacitor. When a read signal reads the data it refreshes it as well. Many different cell designs exist for modern day DRAM cell. These designs are differentiated by the no. of transistors used in their designing. As the no. of transistors increase, power dissipation also increases. DRAM is one of the most common and cost efficient random access memory used as 
International Journal of VLSI design \& Communication Systems (VLSICS) Vol.5, No.4, August 2014

main memory for workstations. The charge stored in memory cell is time dependent. For high density memories DRAM cell with low power consumption and less area are preferred.

The area efficiency of the memory array, i.e., the number of stored data bits per unit area, is one of the key design criteria that determine the overall storage capacity and, hence, the memory cost per bit. Another important issue is the memory access time, i.e., the time required to store and/or retrieve a particular data bit in the memory array. The access time determines the memory speed, which is an important performance criterion of the memory array. Finally, the static and dynamic power consumption of the memory array is a significant factor to be considered in the design, because of the increasing importance of low-power applications. In the following, we will investigate different types of MOS memory arrays and discuss in detail the issues of area, speed, and power consumption for each circuit type Read-write (R/W) memory circuits, on the other hand, must permit the modification (writing) of data bits stored in the memory array, as well as their retrieval (reading) on demand. This requires that the data storage function be volatile, i.e., the stored data are lost when the power supply voltage is turned off. The read-write memory circuit is commonly called Dynamic Random Access Memory (RAM), mostly due to historical reasons. Compared to sequential-access memories such as magnetic tapes, any cell in the R/W memory array can be accessed with nearly equal access time.[3]

\section{LITREATURE SURVEY}

\subsection{T1C DRAM Cell:}

The information is stored as different charge levels at a capacitor in conventional 1T/1C DRAM. The advantage of using DRAM is that it is structural simple: only one transistor and capacitor are required for storing one bit, compared to six transistors required in SRAM. This allows DRAM to have a very high density. The DRAM industry has advanced over a period of time in packing more and more memory bits per unit area on a silicon die. But, the scaling for the conventional 1Transistor/1Capacitor (1T/1C) DRAM is becoming increasingly difficult, in particular due to a capacitor has become harder to scale, as device geometries shrink. Apart from the problems associated with the scaling of the capacitor, scaling also introduces yet another major problem for the DRAM manufacturers which is the leakage current.

\subsection{T DRAM Cell:}

The cell structure shown in fig. 3 is a 4T DRAM cell structure. This DRAM cell design consists of four transistors. One transistor is used as a write transistor, the other as a read transistor. Data in DRAM is stored in the form of charge at the capacitance attached with the transistor structure. There is no current path to the storage node for restoring the data; hence data is lost due to leakage with the period of time. Read operation for the 4T DRAM cell is non-destructive, as the voltage at the storage node is maintained. 


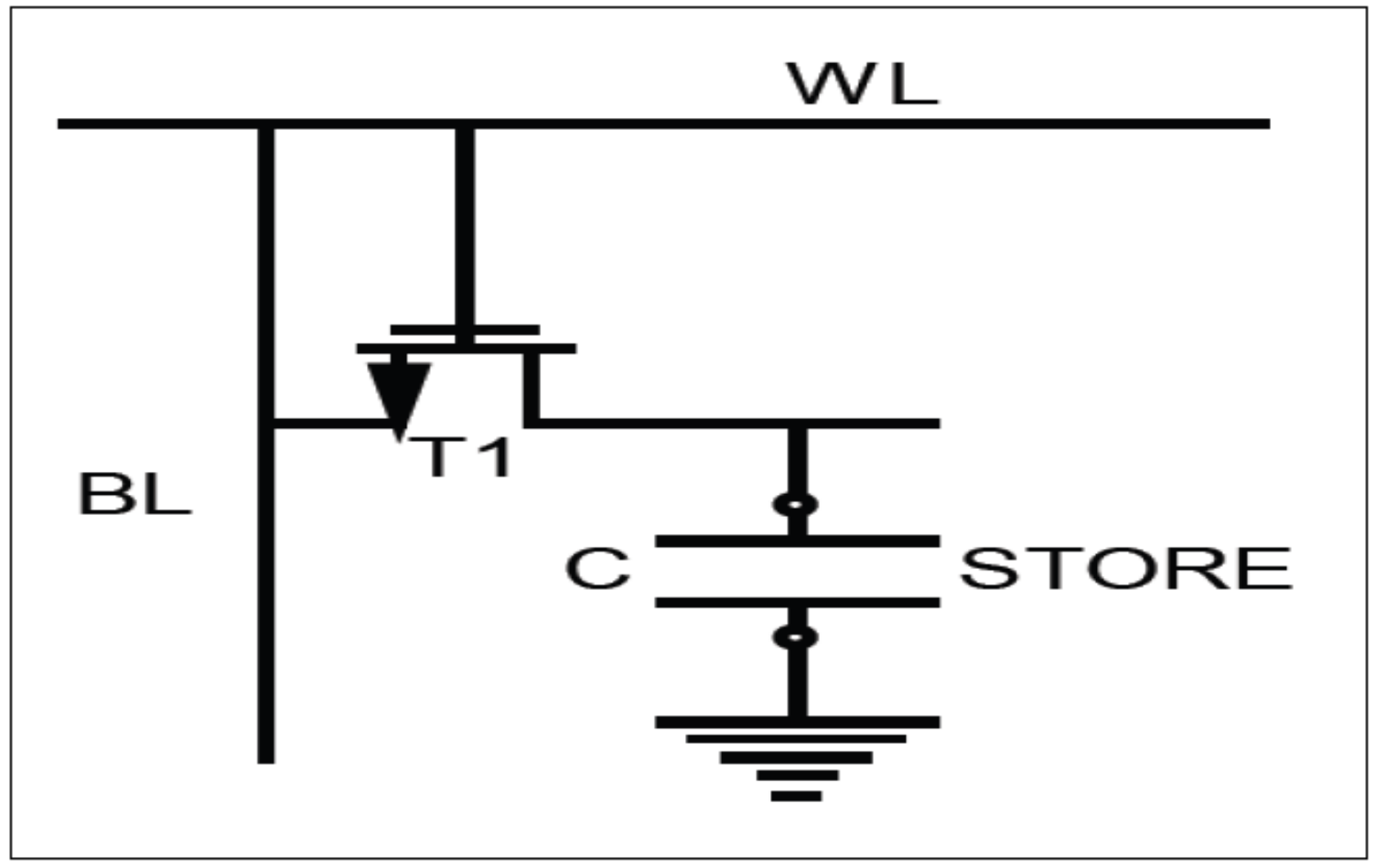

Fig. 1 Schematic 1T1C DRAM cell

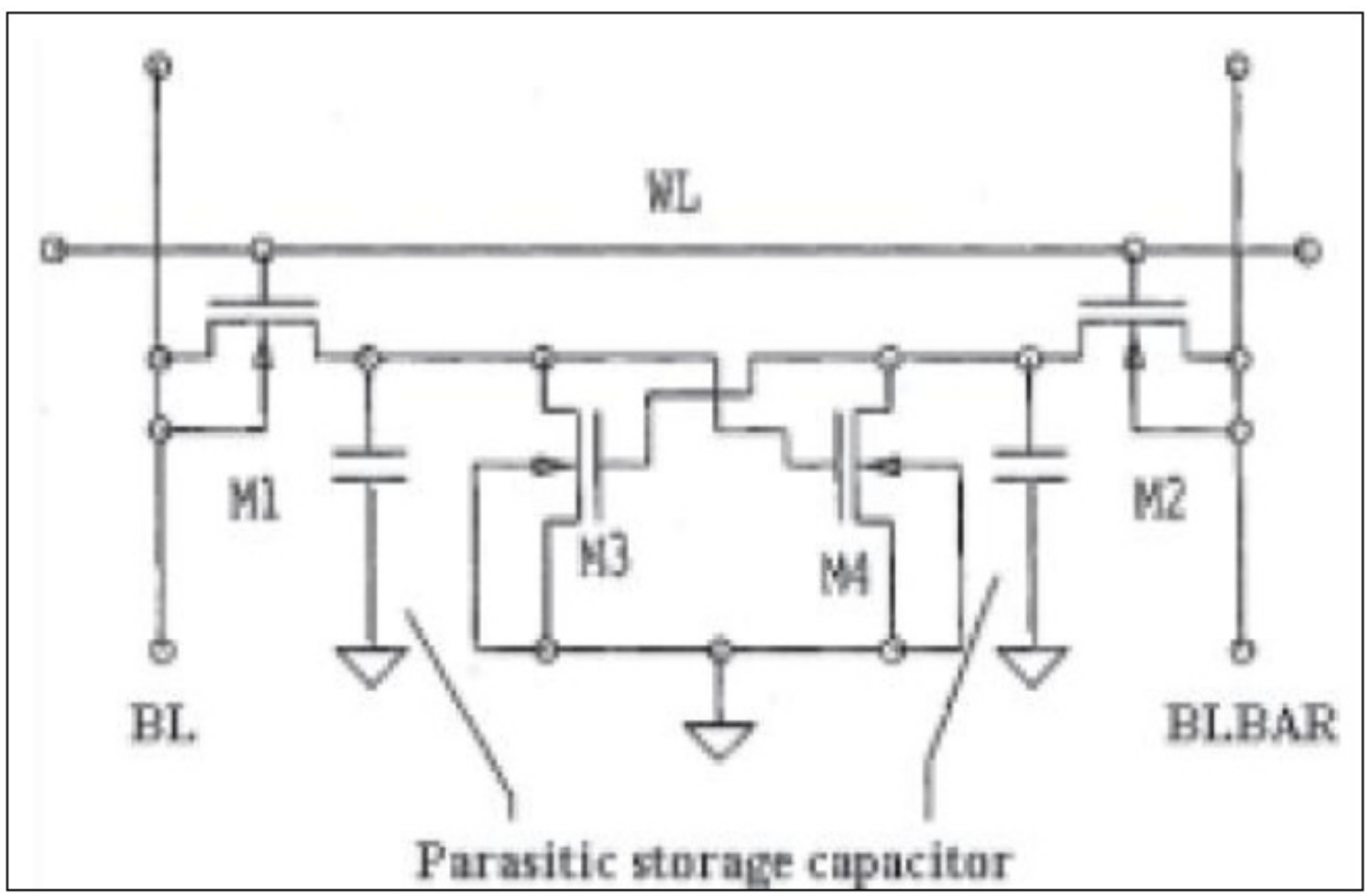

Fig. 2 4T DRAM CELL 
International Journal of VLSI design \& Communication Systems (VLSICS) Vol.5, No.4, August 2014

\subsection{T DRAM Cell:}

The simplest DRAM cell is the 3T scheme. A 3T DRAM cell has a higher density than a SRAM cell; moreover in a 3T DRAM, there is no constraint on device ratios and the read operation is nondestructive. In this cell, the storage capacitance is the gate capacitance of the readout device, so making this scheme attractive for embedded memory applications; however, a 3T DRAM shows still limited performance and low retention time to severely limit its use in advanced integrated circuits.3T DRAM utilizes gate of the transistor and a capacitance to store the data value. When data is to be written, write signal is enabled and the data from the bit line is fed into the cell. When data is to be read from the cell, read line is enabled and data is read through the bit line. 3T DRAM cell occupies less area compared to the 4T DRAM cell (fig. 4).

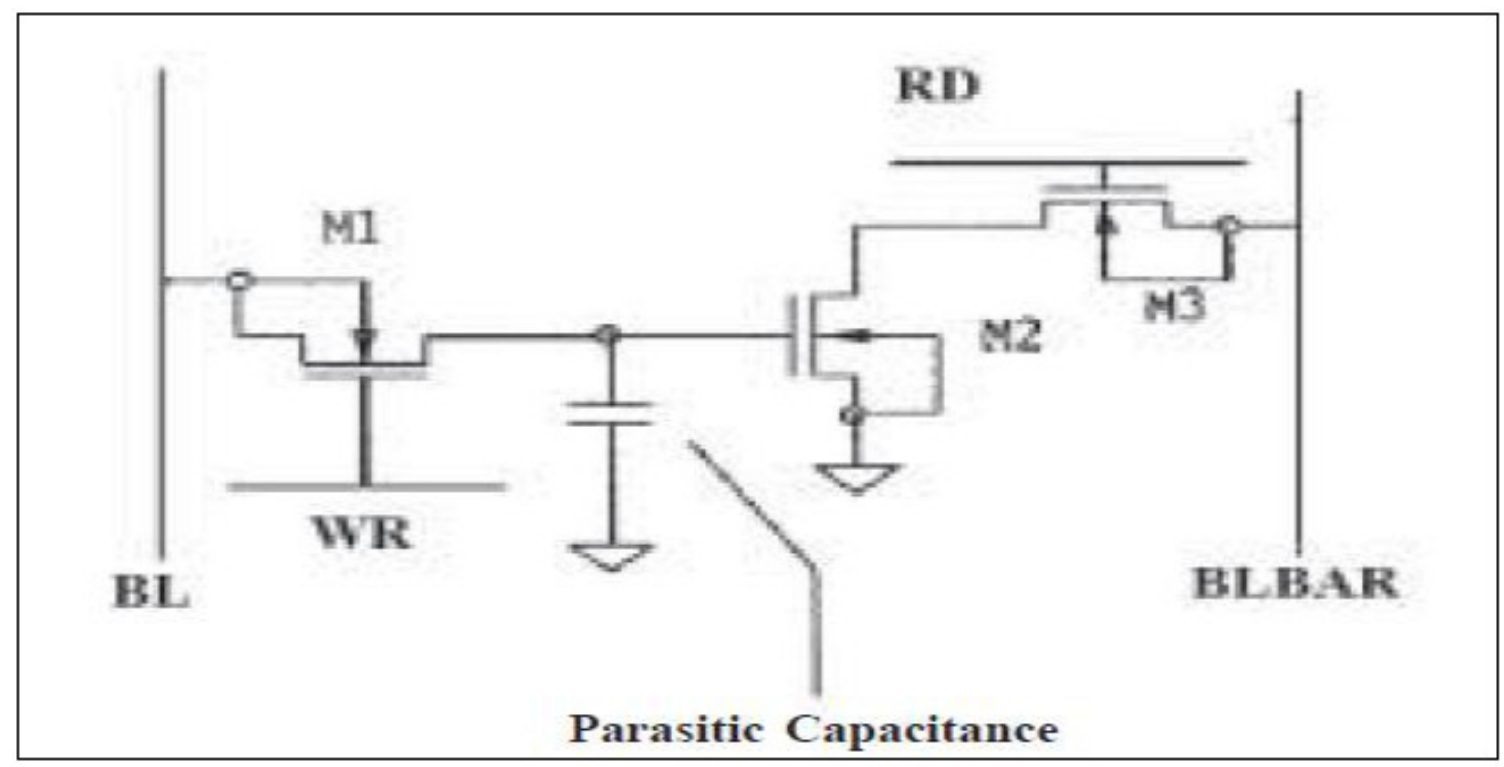

Fig. 3 3T DRAM CELL

\subsection{T1D DRAM Cell:}

This is a DRAM structure derived from 3T cell, like all DRAM it uses few transistor compared to static random access memory (SRAM). The 3T1D has an advantage over SRAM, is its resistance to process variation, this feature helps it to be used at low feature sizes. Another advantage of 3T1D DRAM is that it does not slow down as its size is scaled down.3T1D DRAM uses the gated diode instead of capacitor to store the data value. The absence of capacitor provides significance reduction in power consumption as compared to previous DRAM cell design.In order to write the cell at the BL write line level, it is only required to activate T1 through the WL write line. Hence, the $\mathrm{S}$ node stores either a 0 or a VDD-Vth voltage depending on the logic value. This voltage results in the accumulation of charge at the gate of devices D1 and T2. [2]

The 3T1D cell in fig. 5 shows the scheme of the basic cell. The basis of the storage system is the charge placed in node $\mathrm{S}$, written from BL write line when $\mathrm{T} 1$ is activated. Consequently, it has a DRAM cell nature, but it allows a non-destructive read process (a clear advantage over 1T1C memories) and high performance read and writes operation, comparable to 6T.With T1 and T3 
International Journal of VLSI design \& Communication Systems (VLSICS) Vol.5, No.4, August 2014

transistors as accessing devices, the whole cell is composed by four transistors of similar size to the corresponding of $6 \mathrm{~T}$.

This implies a more compact cell structure. In order to write the cell at the BL write line level it is only required to activate T1 through the WL write line. Hence, the S node stores either a 0 or a VDD-Vth voltage depending on the logic value. This voltage results in the accumulation of charge at the gate of devices D1 and T2.A key aspect of the 3T1D memory cell is that the capacitance of the gated diode (D1) when Vgs is above Vth is significantly higher with respect to lower voltages, because there is a substantial amount of charge stored in the inversion layer.

In order to read the cell, the read bit line BL read has to be previously pre-charged at VDD level. Then T3 is activated from WL read line. If a high (1) level is stored in S, transistor T2 turns on and discharges the bit line. If a low (0) level is stored in S, transistor T2 does not reach enough conduction level. The objective of the gated diode D1 is to improve Read Access Time. When a high (1) level is stored in S, D1 connected to WL read line causes a boosting effect of the voltage level in node $S$. The voltage level reached at node $S$ is close to Vdd voltage causing a fast discharge of the parasitic capacitance in BL read. If allow (0) level is stored, transistor T2 keeps turned off. [9]

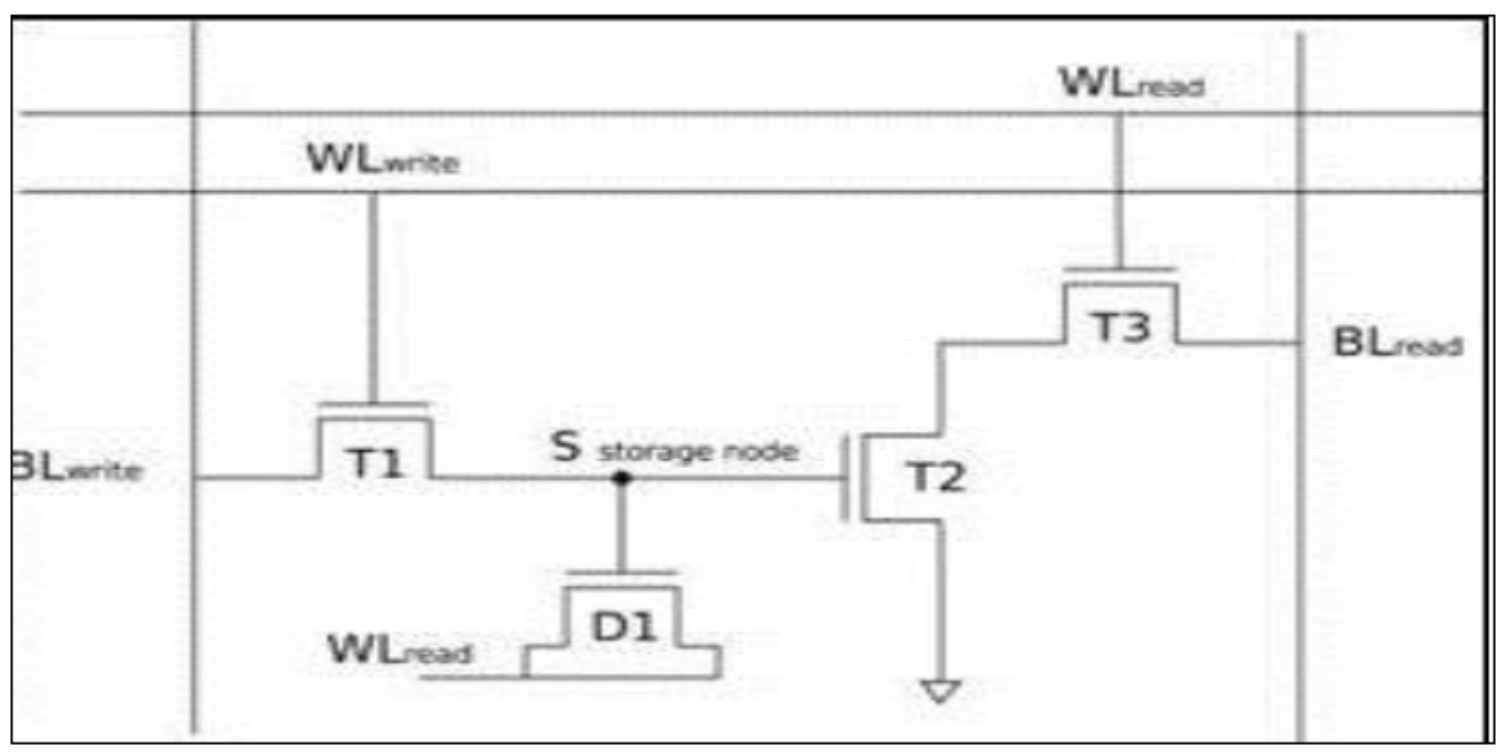

Fig. 4 3T1D DRAM CELL

\section{SCHEMATICS OF CELLS}

All simulation carried out on TANNER EDA 14.0 with model file of $32 \mathrm{~nm}$ high performance taken from PTM. Tool used for circuit design is SEDIT and for simulation is TSPICE. 
International Journal of VLSI design \& Communication Systems (VLSICS) Vol.5, No.4, August 2014

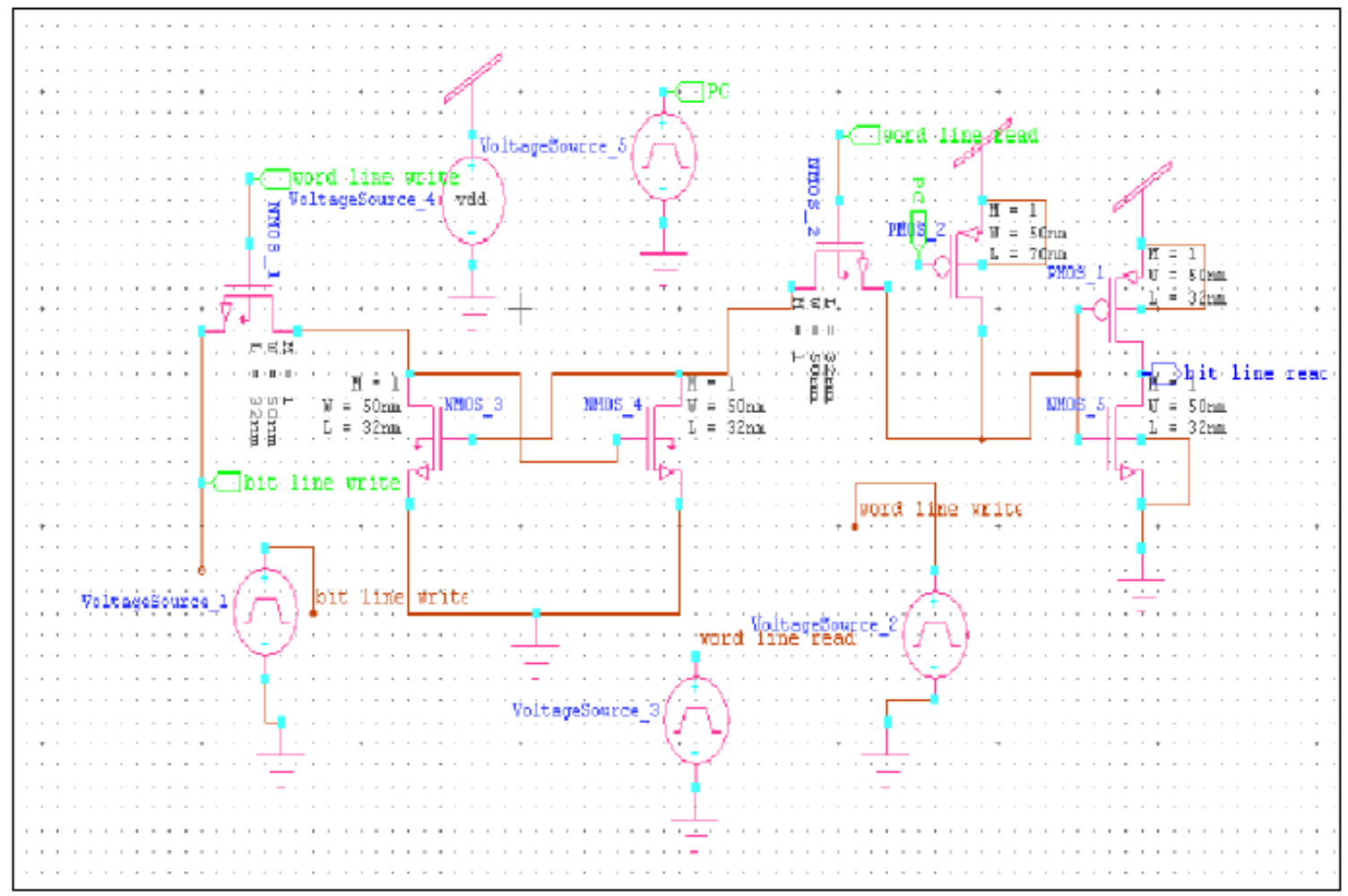

Fig. 5 Schematic of 4T DRAM

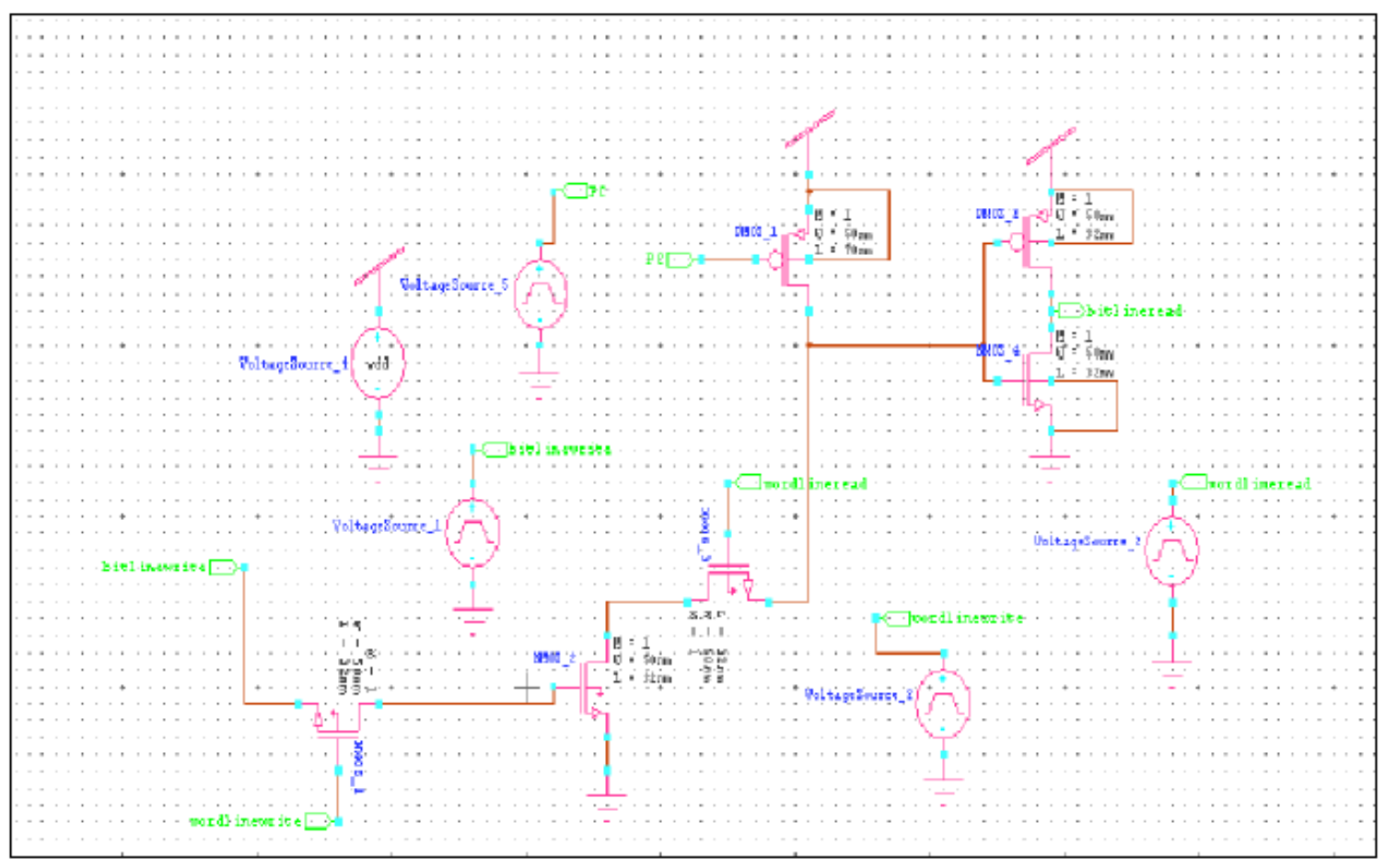

Fig.6 Schematic of 3T DRAM 
International Journal of VLSI design \& Communication Systems (VLSICS) Vol.5, No.4, August 2014

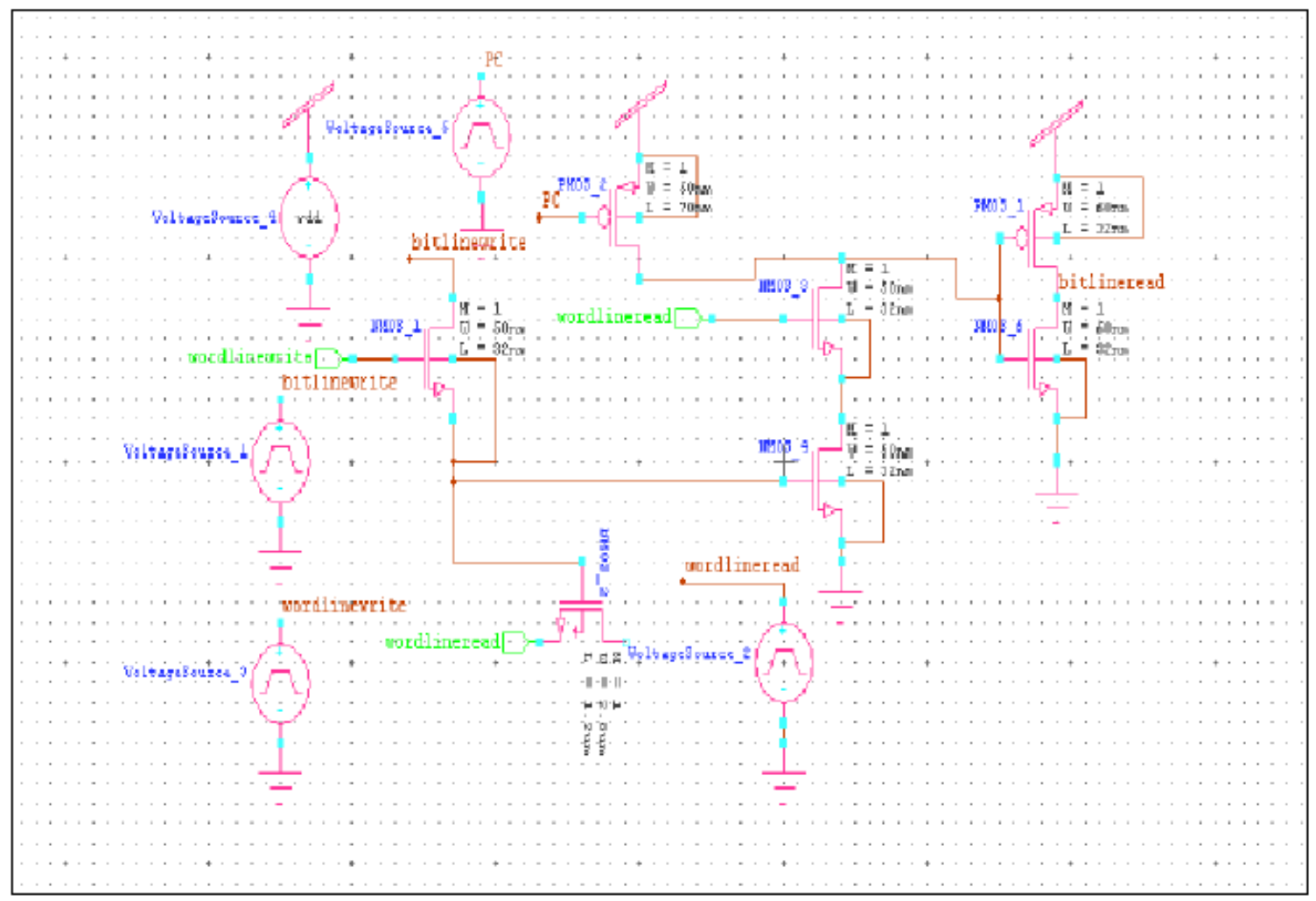

Fig.7 Schematic of 3T1D DRAM

\section{SiMULATION RESULTS}

Simulation for all five cells 4T, 3T, and 3T1D design are carried out from 0-10 ns. During this interval all the four process write ' 0 ', write ' 1 ', read ' 0 ' and read ' 1 ', are executed. Average power consumption is calculated for the full $0-10 \mathrm{~ns}$ duration consisting of all four operations.

Table1. Operation of waveforms

\begin{tabular}{|c|c|}
\hline Operation & Time Period \\
\hline WRITE ‘ 1 ' & $2-3 \mathrm{~ns}$ \\
\hline READ ‘' $’$ & $4-5 \mathrm{~ns}$ \\
\hline WRITE ‘0’ & $6-7 \mathrm{~ns}$ \\
\hline READ ‘0’ & $8-9 \mathrm{~ns}$ \\
\hline
\end{tabular}


International Journal of VLSI design \& Communication Systems (VLSICS) Vol.5, No.4, August 2014

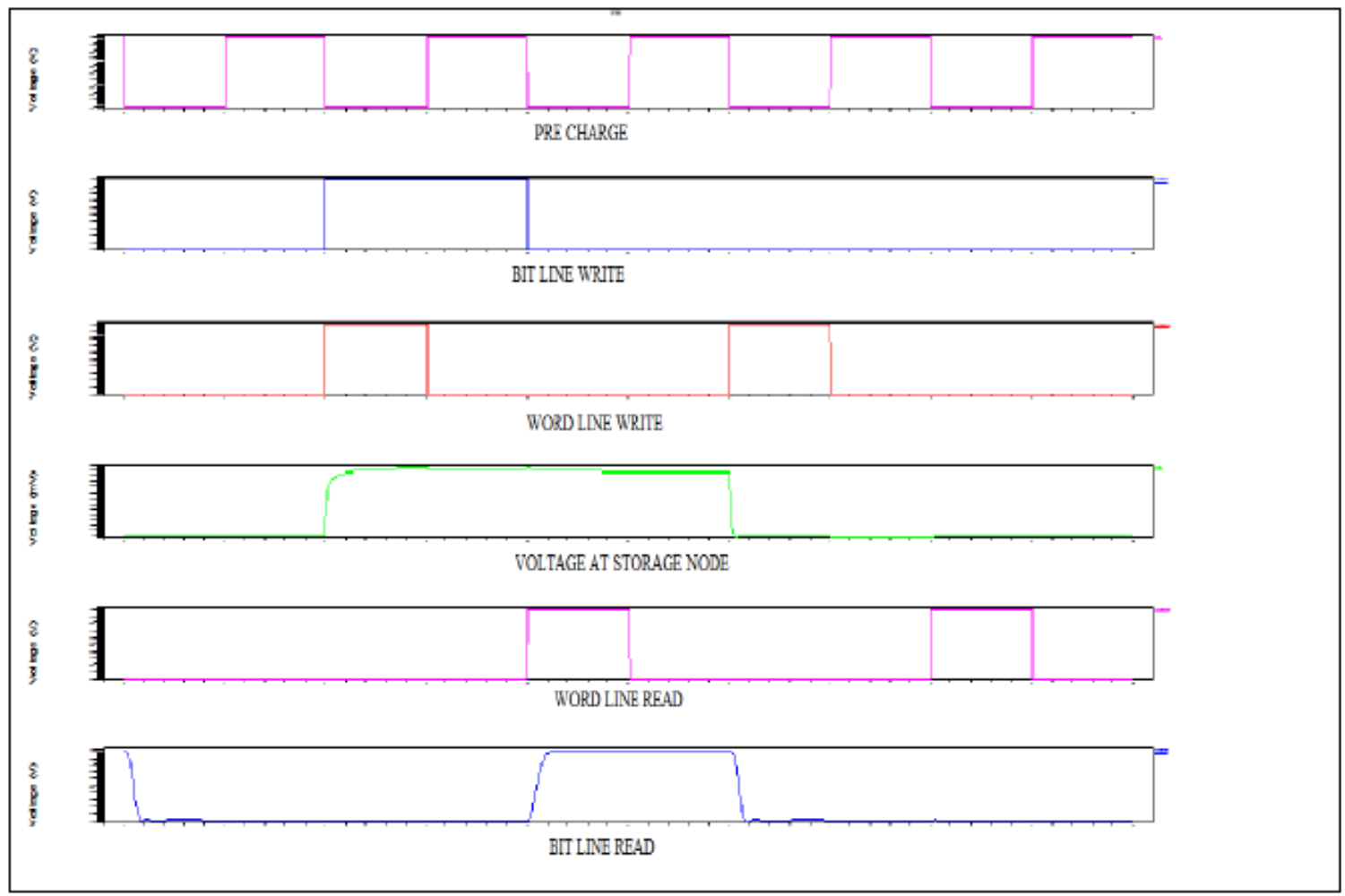

Fig.8 Read Write operation of 4T DRAM Cell

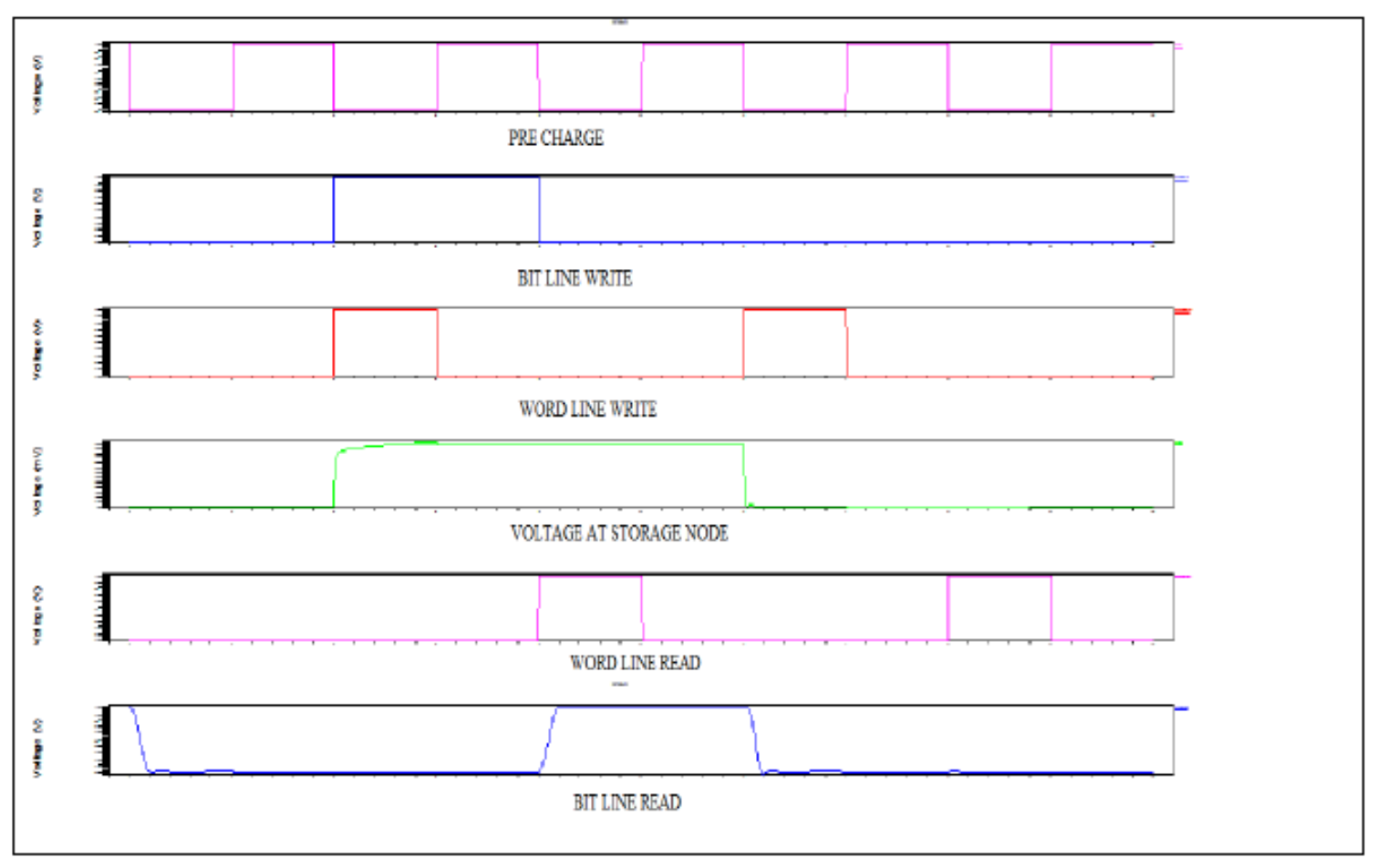

Fig.9 Read Write operation of 3T DRAM Cell 
International Journal of VLSI design \& Communication Systems (VLSICS) Vol.5, No.4, August 2014

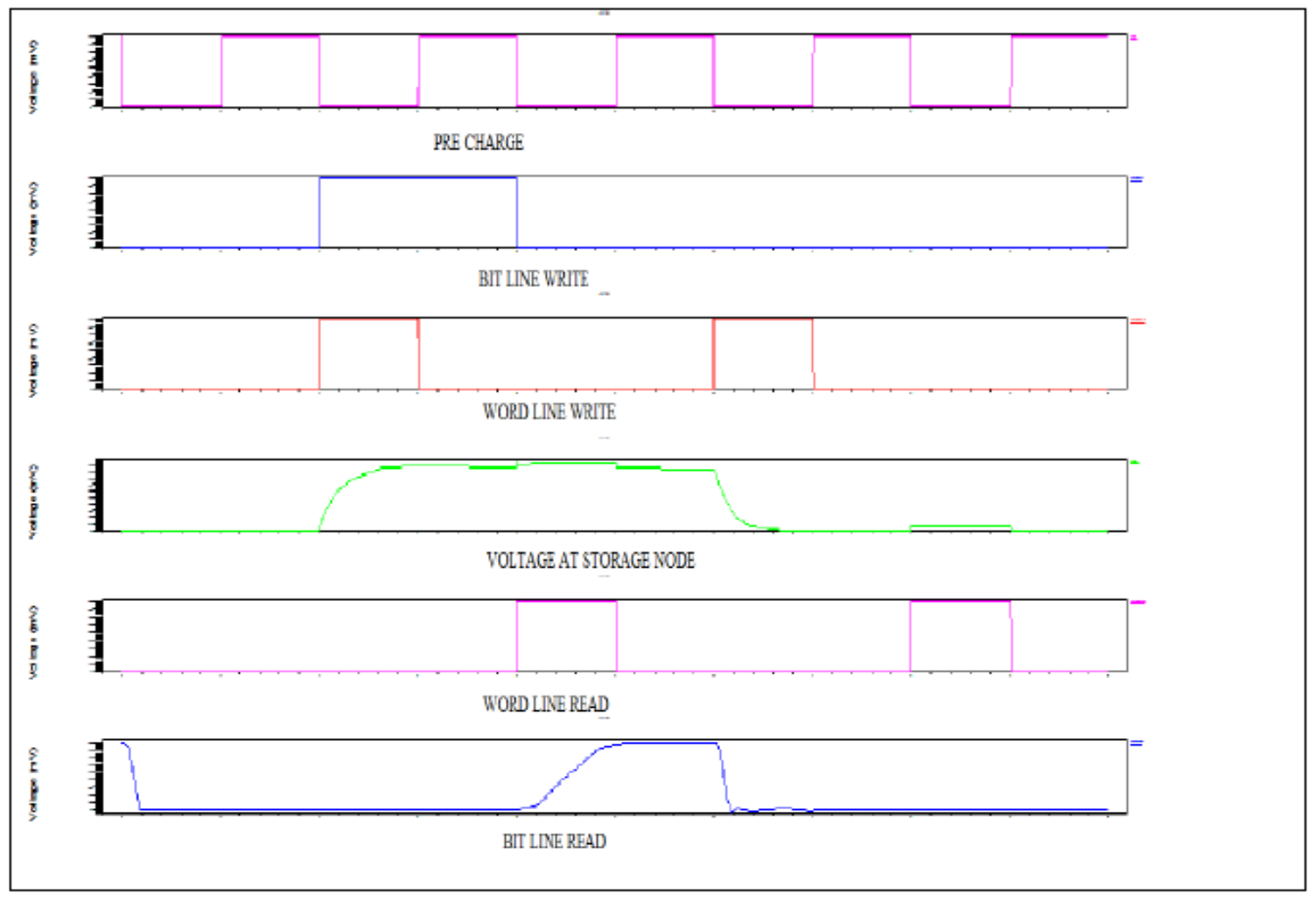

Fig.10 Read Write operation of 3T1D DRAM Cell

\section{PERFORMANCE ANALYSiS}

Average power consumption foe 4T, 3T, 3T1D, gain 3T and Power modified 3T1D is carried out. The average power consumption value is calculated with varying temperature form $20^{\circ} \mathrm{C}$ to $100^{\circ} \mathrm{C}$. It is essential to perform power v/s temperature as it gives an idea about the average power consumption of the cell design when it is subjected to high temperature.

Table2. Average Power Consumption V/S Supply Voltage

\begin{tabular}{|c|c|c|c|}
\hline $\begin{array}{c}\text { SUPPLY VOLTAGE } \\
\text { (volt) }\end{array}$ & $\begin{array}{c}\text { AVERAGE POWER } \\
\text { CONSUMPTION } \\
\text { FOR 4T ( u watt) }\end{array}$ & $\begin{array}{c}\text { AVERAGE POWER } \\
\text { CONSUMPTION FOR } \\
\text { 3T ( u watt) }\end{array}$ & $\begin{array}{c}\text { AVERAGE POWER } \\
\text { CONSUMPTION FOR } \\
\text { 3T1D ( u watt) }\end{array}$ \\
\hline 0.7 & 0.1656537 & 0.2507752 & 0.1299199 \\
\hline 0.8 & 0.2625748 & 0.6496773 & 0.3846698 \\
\hline 0.9 & 0.6618851 & 1.167894 & 1.255590 \\
\hline 1 & 1.739659 & 1.662307 & 1.566112 \\
\hline 1.1 & 2.384711 & 2.262632 & 2.170092 \\
\hline
\end{tabular}


International Journal of VLSI design \& Communication Systems (VLSICS) Vol.5, No.4, August 2014

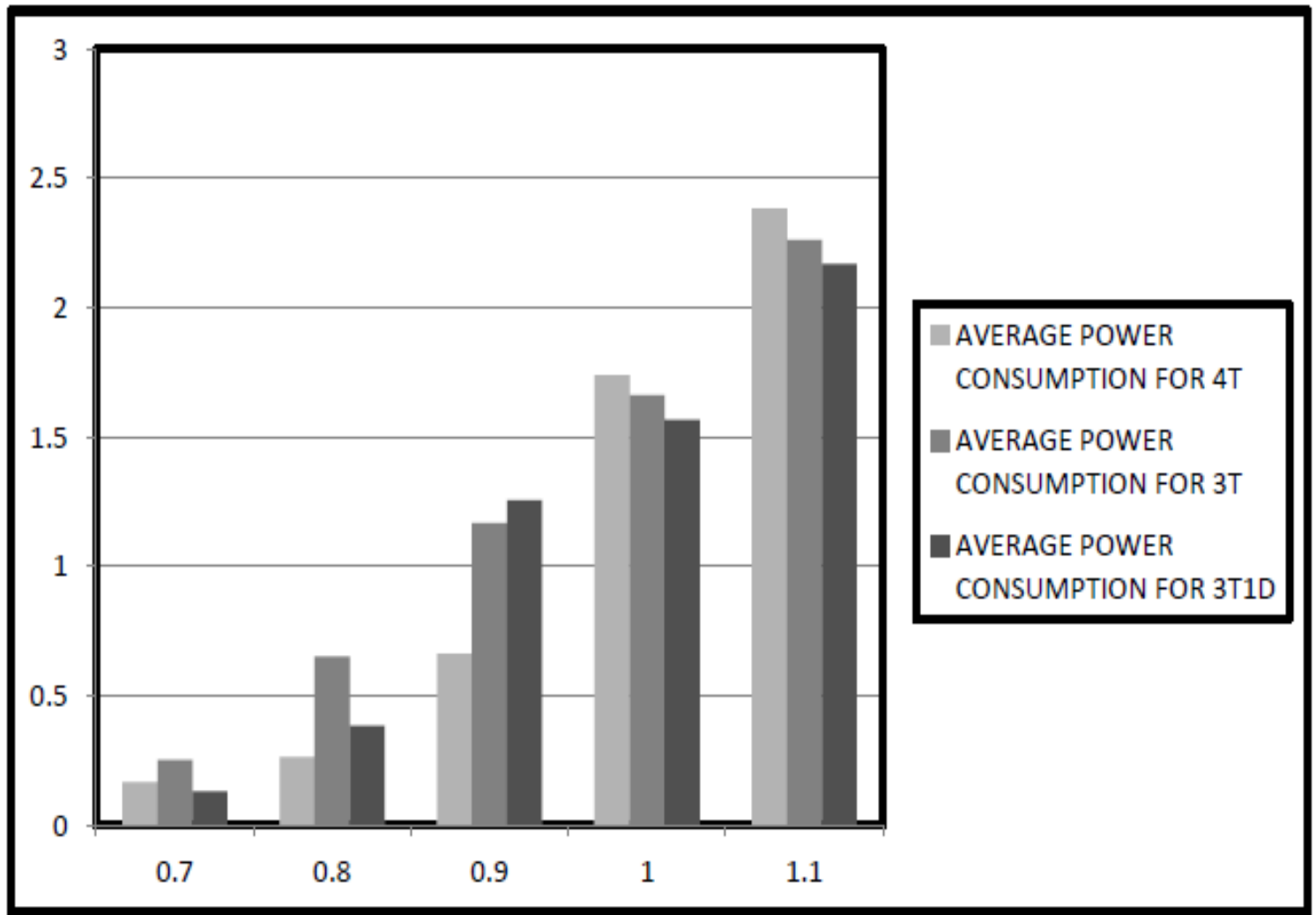

Fig. 11 Bar chart comparing power consumption of dram cell with supply voltage

Table3. Write Access Time V/S Supply Voltage

\begin{tabular}{|c|c|c|c|}
\hline $\begin{array}{c}\text { SUPPLY VOLTAGE } \\
\text { (volt) }\end{array}$ & $\begin{array}{c}\text { WRITE ACCESS } \\
\text { TIME FOR 4T (p sec) }\end{array}$ & $\begin{array}{c}\text { WRITE ACCESS } \\
\text { TIME FOR 3T (p sec) }\end{array}$ & $\begin{array}{c}\text { WRITE ACCESS } \\
\text { TIME FOR 3T1D } \\
\text { (p sec) }\end{array}$ \\
\hline 0.7 & 25.43 & 16.6 & 230.09 \\
\hline 0.8 & 27.28 & 17.66 & 281.40 \\
\hline 0.9 & 26.96 & 17.56 & 291.17 \\
\hline 1 & 35.73 & 19.53 & 299.35 \\
\hline 1.1 & 37.45 & 20.89 & 385.45 \\
\hline
\end{tabular}


International Journal of VLSI design \& Communication Systems (VLSICS) Vol.5, No.4, August 2014

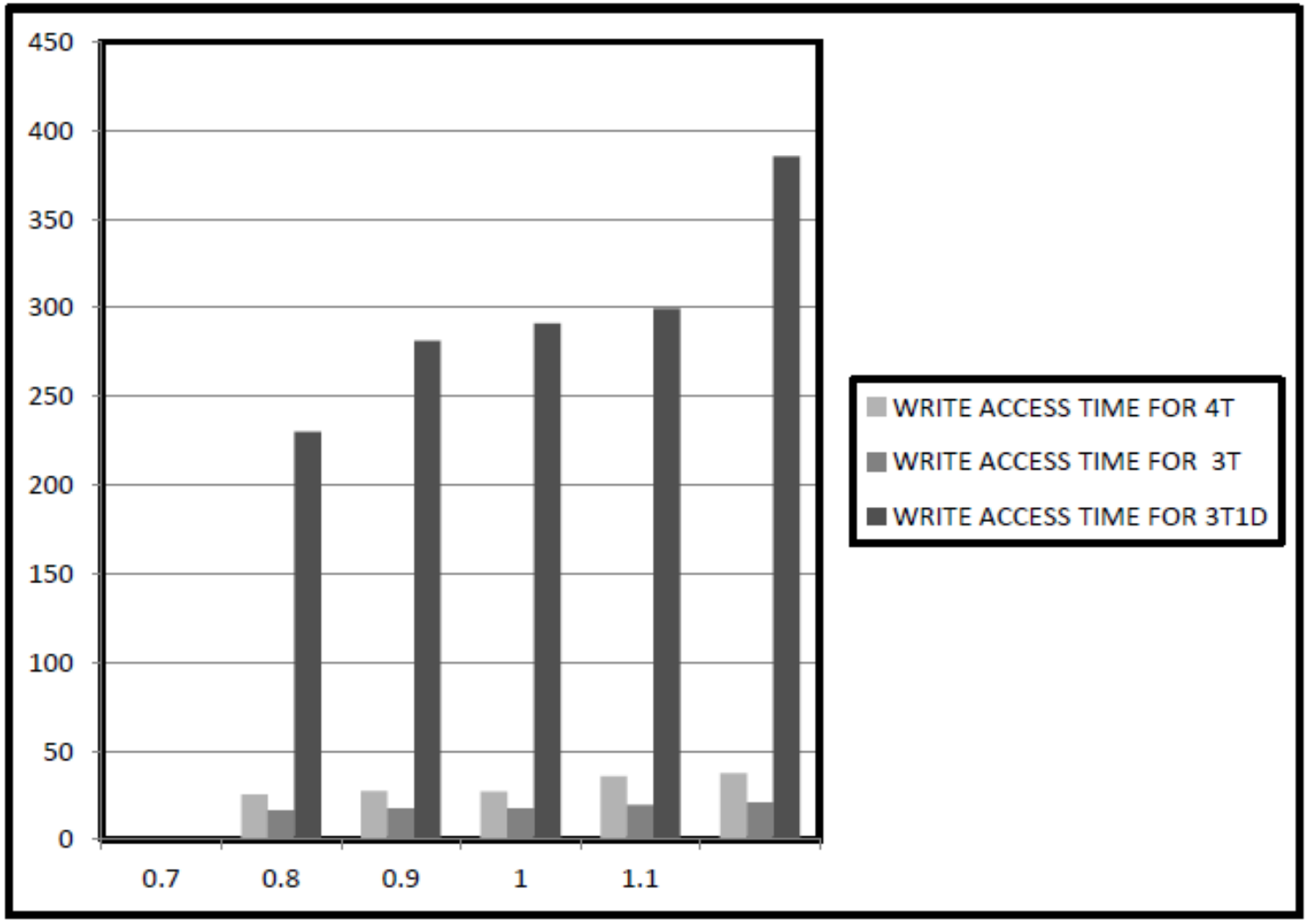

Fig. 12 Bar chart comparing write access time of DRAM cell with supply voltage

Table 4. Read Access Time V/S Supply Voltage

\begin{tabular}{|c|c|c|c|}
\hline $\begin{array}{c}\text { SUPPLY VOLTAGE } \\
\text { (volt) }\end{array}$ & $\begin{array}{c}\text { READ ACCESS TIME } \\
\text { FOR 4T (p sec) }\end{array}$ & $\begin{array}{c}\text { READ ACCESS TIME } \\
\text { FOR 3T (p sec) }\end{array}$ & $\begin{array}{c}\text { READ ACCESS TIME } \\
\text { FOR 3T1D (p sec) }\end{array}$ \\
\hline 0.7 & ---- & ---- & --- \\
\hline 0.8 & ---- & --- & 506.43 \\
\hline 0.9 & ---- & 181.86 & 103.40 \\
\hline 1 & 100.87 & 87.72 & 68.65 \\
\hline 1.1 & 71.19 & 70.7 & \\
\hline
\end{tabular}


International Journal of VLSI design \& Communication Systems (VLSICS) Vol.5, No.4, August 2014

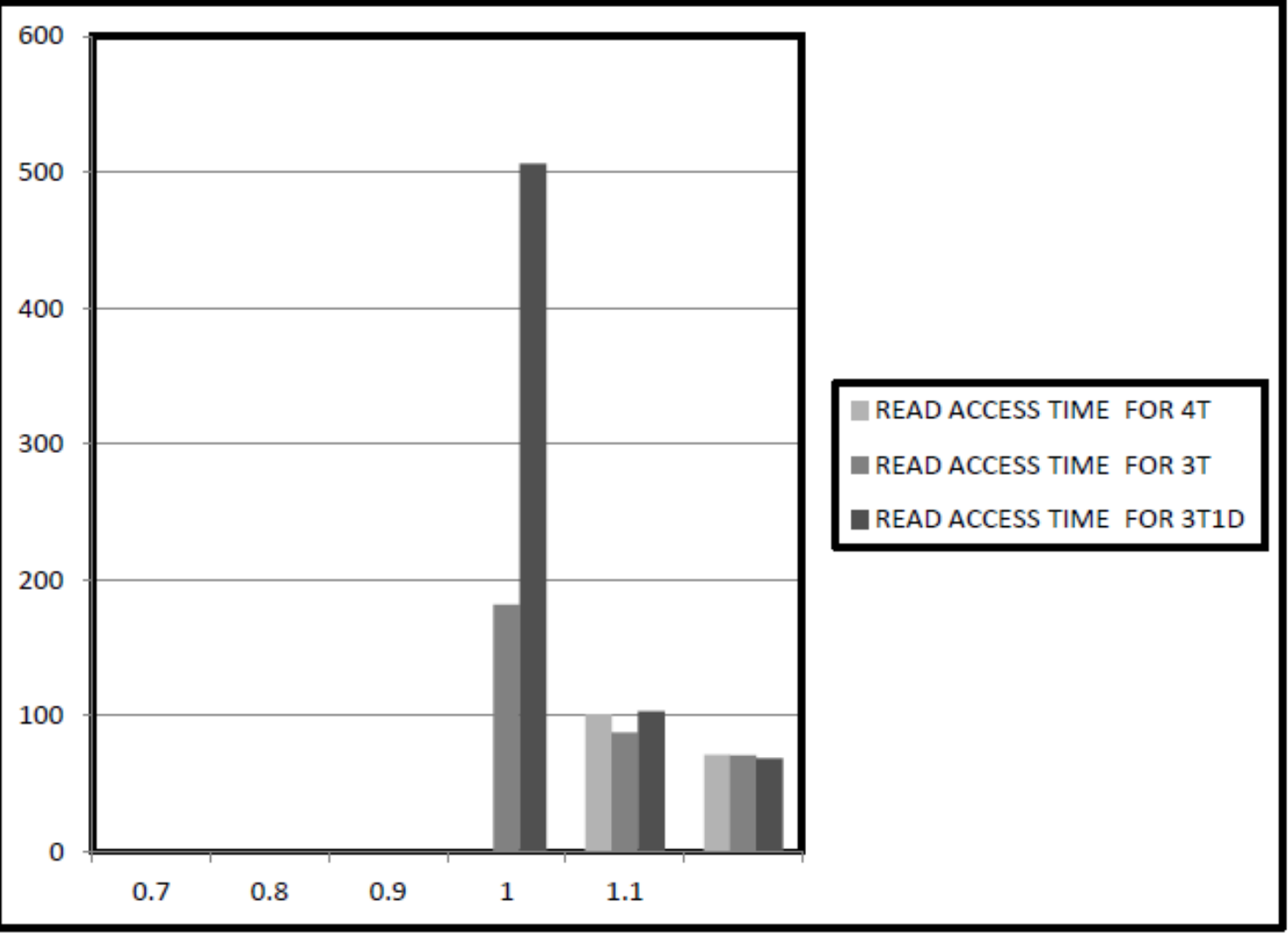

Fig. 13 Bar chart comparing read access time of DRAM cell with supply voltage

Table 5. Retention Time V/S Supply Voltage

\begin{tabular}{|c|c|c|c|}
\hline $\begin{array}{c}\text { SUPPLY VOLTAGE } \\
\text { (volt) }\end{array}$ & $\begin{array}{c}\text { RETENTION TIME } \\
\text { FOR 4T (u sec) }\end{array}$ & $\begin{array}{c}\text { RETENTION TIME } \\
\text { FOR 3T (u sec) }\end{array}$ & $\begin{array}{c}\text { RETENTION TIME } \\
\text { FOR 3T1D (u sec) }\end{array}$ \\
\hline 0.7 & 4.54378 & 5.31742 & 66.44272 \\
\hline 0.8 & 4.02719 & 4.50587 & 59.30578 \\
\hline 0.9 & 3.09407 & 3.44944 & 52.44869 \\
\hline 1 & 2.61674 & 3.74946 & 45.55423 \\
\hline 1.1 & 2.45621 & 3.49827 & 40.07223 \\
\hline
\end{tabular}


International Journal of VLSI design \& Communication Systems (VLSICS) Vol.5, No.4, August 2014

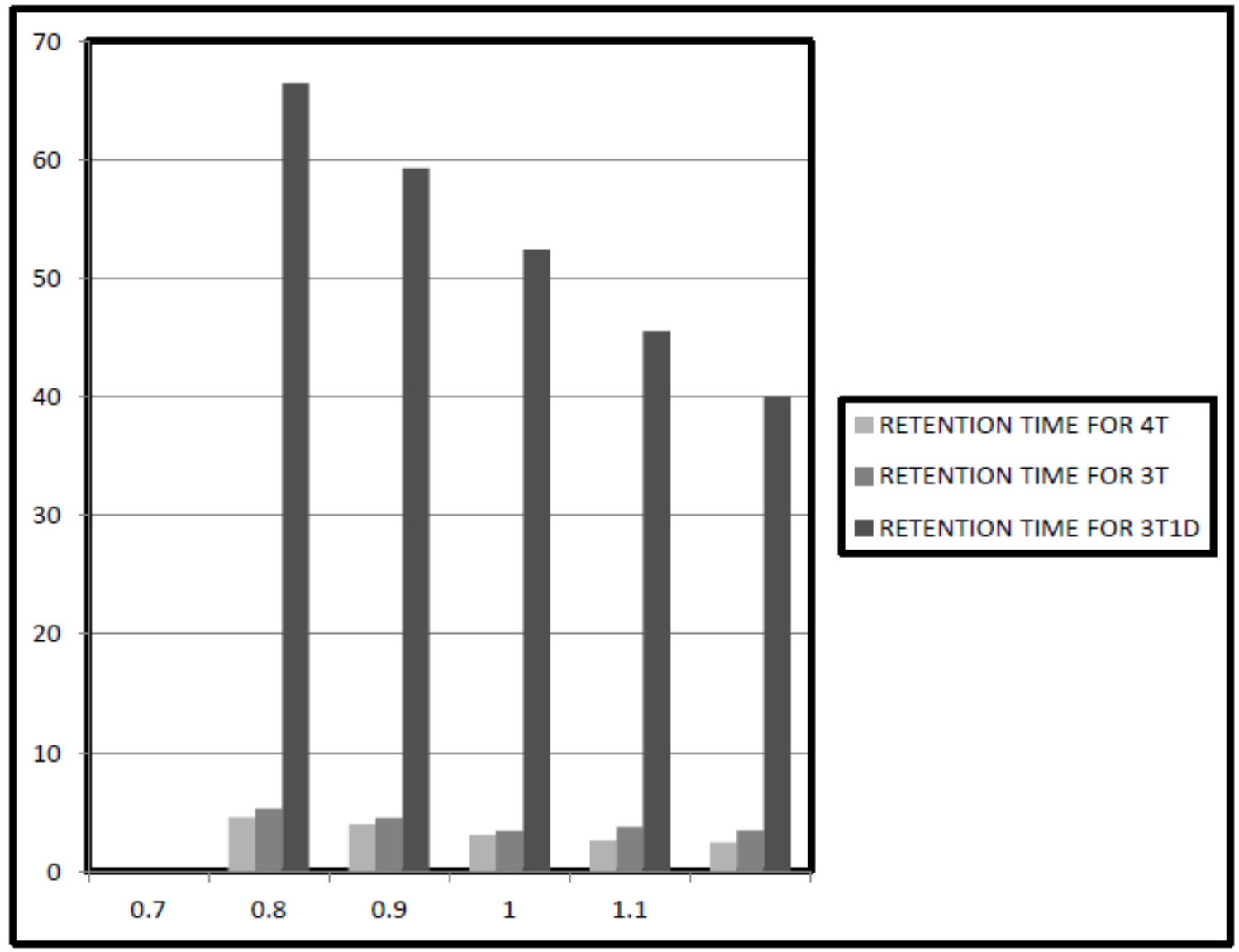

Fig. 14 Bar chart comparing retention time of dram cell with supply voltage

Table6. Average Power Consumption V/S Temperature

\begin{tabular}{|c|c|c|c|}
\hline TEMPERATURE $\left({ }^{\circ} \mathrm{C}\right)$ & $\begin{array}{c}\text { AVERAGE POWER } \\
\text { CONSUMPTION FOR } \\
\text { 4T(u watt) }\end{array}$ & $\begin{array}{c}\text { AVERAGE POWER } \\
\text { CONSUMPTION FOR } \\
\text { 3T(u watt) }\end{array}$ & $\begin{array}{c}\text { AVERAGE POWER } \\
\text { CONSUMPTION FOR } \\
\text { 3T1D(u watt) }\end{array}$ \\
\hline 20 & 0.6458878 & 1.1675897 & 1.2555492 \\
\hline 30 & 0.6470248 & 1.1724360 & 1.2639104 \\
\hline 40 & 0.6481929 & 1.1745580 & 1.2675122 \\
\hline 50 & 0.6494720 & 1.1762466 & 1.2729316 \\
\hline 60 & 0.6507602 & 1.1775308 & 1.2740492 \\
\hline 70 & 0.6517609 & 1.1826280 & 1.2782908 \\
\hline 80 & 0.6527710 & 1.1974269 & 1.2825619 \\
\hline 90 & 0.6536949 & 1.1905366 & 1.2846014 \\
\hline 100 & 0.6546256 & 1.1927739 & 1.2876134 \\
\hline
\end{tabular}


International Journal of VLSI design \& Communication Systems (VLSICS) Vol.5, No.4, August 2014

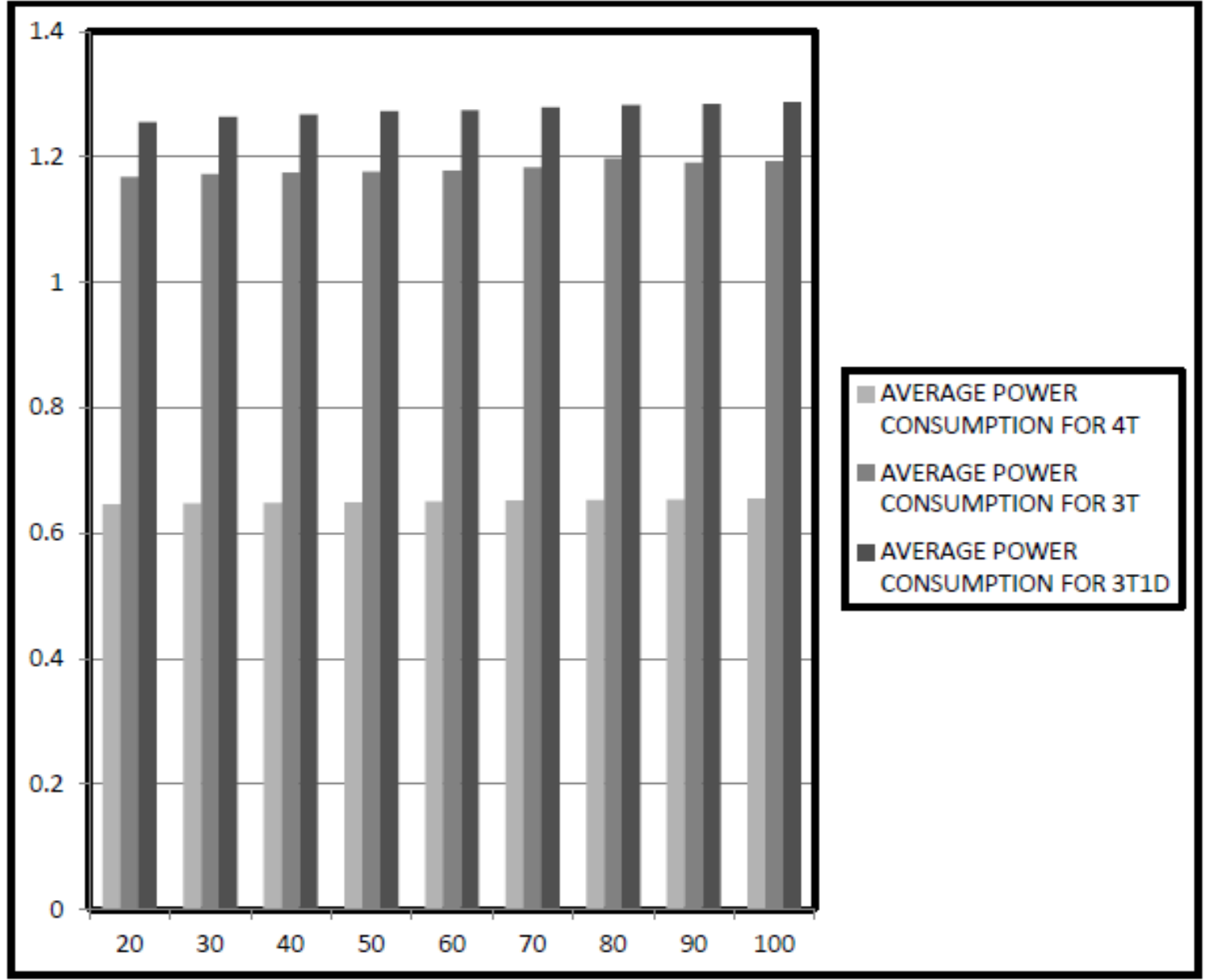

Fig. 15 Bar chart comparing average power consumption of dram cell with temperature

Table7. Write Access Time V/S Temperature

\begin{tabular}{|c|c|c|c|}
\hline TEMPERATURE $\left({ }^{\mathbf{0}} \mathbf{C}\right)$ & $\begin{array}{c}\text { WRITE ACCESS } \\
\text { TIME FOR 4T (p sec) }\end{array}$ & $\begin{array}{c}\text { WRITE ACCESS } \\
\text { TIME FOR 3T (p sec) }\end{array}$ & $\begin{array}{c}\text { WRITE ACCESS } \\
\text { TIME FOR 3T1D } \\
\text { (p sec) }\end{array}$ \\
\hline 20 & 26.96 & 17.56 & 291.17 \\
\hline 30 & 28.7 & 18.10 & 295.57 \\
\hline 40 & 30.5 & 18.84 & 297.88 \\
\hline 50 & 32.29 & 20.05 & 301.30 \\
\hline 60 & 33.97 & 22.71 & 303.67 \\
\hline 70 & 35.64 & 25.60 & 307.14 \\
\hline 80 & 37.26 & 28.25 & 309.64 \\
\hline 90 & 38.79 & 30.52 & 312.94 \\
\hline 100 & 39.56 & 32.73 & 316.40 \\
\hline
\end{tabular}




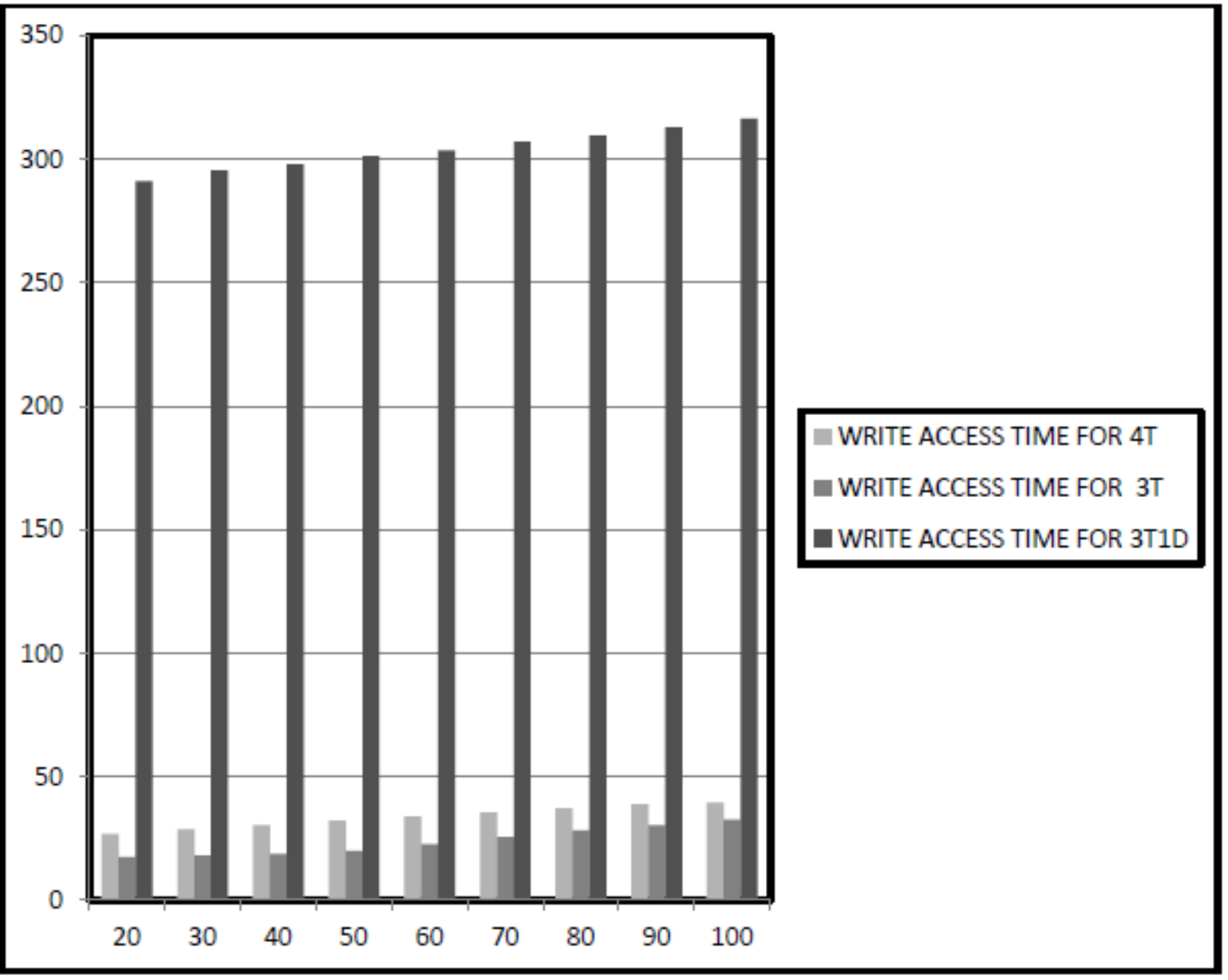

Fig. 16 Bar chart comparing write access time of dram cell with temperature

Table 8. Read Access Time V/S Temperature

\begin{tabular}{|c|c|c|c|}
\hline TEMPERATURE $\left({ }^{\mathbf{0}} \mathbf{C}\right)$ & $\begin{array}{c}\text { READ ACCESS } \\
\text { TIME FOR 4T }(\mathbf{p} \text { sec })\end{array}$ & $\begin{array}{c}\text { READ ACCESS } \\
\text { TIME FOR 3T (p sec) }\end{array}$ & $\begin{array}{c}\text { READ ACCESS } \\
\text { TIME FOR 3T1D } \\
\text { (p sec) }\end{array}$ \\
\hline 20 & 100.87 & 87.72 & 103.40 \\
\hline 30 & 101.12 & 88.14 & 103.81 \\
\hline 40 & 101.72 & 88.27 & 104.78 \\
\hline 50 & 102.18 & 88.70 & 105.20 \\
\hline 60 & 102.49 & 89.03 & 105.92 \\
\hline 70 & 102.98 & 89.26 & 106.86 \\
\hline 80 & 103.07 & 90.36 & 107.46 \\
\hline 90 & 103.25 & 90.80 & 108.10 \\
\hline 100 & 103.51 & 91.23 & 108.72 \\
\hline
\end{tabular}




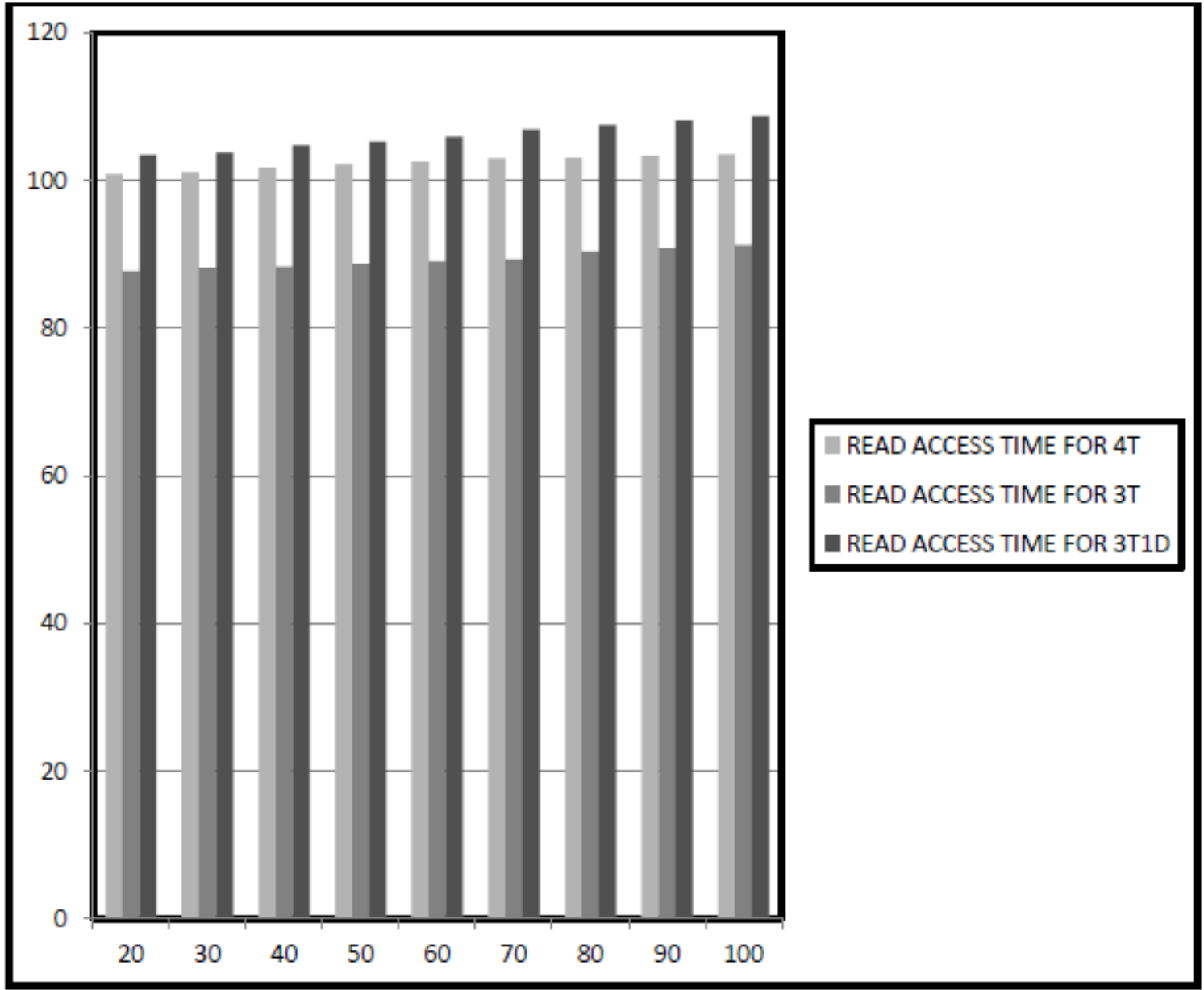

Fig. 17 Bar chart comparing read access time of dram cell with temperature

Table 9. Retention Time V/S Temperature

\begin{tabular}{|c|c|c|c|}
\hline TEMPERATURE ( $\left.{ }^{\mathbf{0}} \mathbf{C}\right)$ & $\begin{array}{c}\text { RETENTION TIME } \\
\text { FOR 4T (u sec) }\end{array}$ & $\begin{array}{c}\text { RETENTION TIME } \\
\text { FOR 3T (u sec) }\end{array}$ & $\begin{array}{c}\text { RETENTION TIME } \\
\text { FOR 3T1D (u sec) }\end{array}$ \\
\hline 20 & 3.09407 & 3.44944 & 52.44869 \\
\hline 30 & 2.69213 & 3.34562 & 52.29345 \\
\hline 40 & 2.55213 & 3.16785 & 51.73567 \\
\hline 50 & 2.28657 & 2.90562 & 51.62558 \\
\hline 60 & 2.18889 & 2.69547 & 50.96833 \\
\hline 70 & 1.98762 & 2.42455 & 50.83636 \\
\hline 80 & 1.74325 & 2.12328 & 50.00756 \\
\hline 90 & 1.46567 & 1.93544 & 49.74578 \\
\hline 100 & 1.23789 & 1.18882 & 49.34875 \\
\hline
\end{tabular}




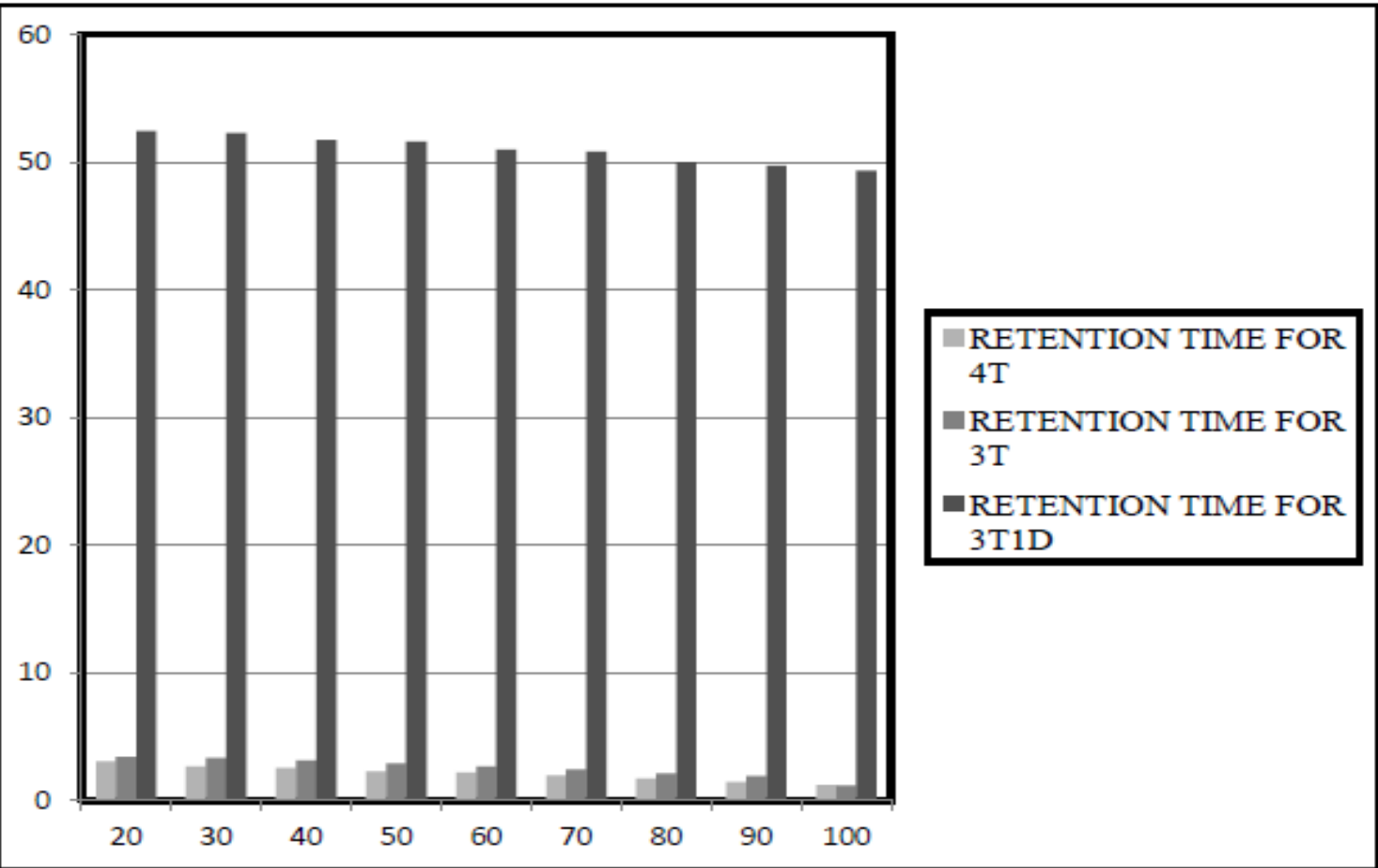

Fig. 18 Bar chart comparing retention time of dram cell with temperature

\section{CONCLUSION}

The study of 4T DRAM cell, 3T DRAM cell and 3T1D DRAM cell for average power consumption, write access time, read access time and retention time has been carried out. These parameters are studied in accordance with variation of supply voltage FROM 0.7, 0.8, 0.9, 1.0, $1.1 \mathrm{~V}$.

Analysis of Average Power Consumption shows that 3T1D DRAM cell has the least average power consumption compared to 4T DRAM and 3T DRAM cell. Average Power Consumption tends to increase as the supply voltage increases.

Analysis of Write Access Time shows that 3T DRAM cell has the least write access time compared to 4T DRAM and 3T1D DRAM cell. Write Access Time of 3T1D DRAM is significantly more than that of 3T and 4T DRAM cell. Write Access Time tends to increase as the supply voltage increases.

Analysis of Read Access Time shows that 3T DRAM cell has the least read access time compared to 4T DRAM and 3T1D DRAM cell. Read Access Time of 3T1D DRAM is significantly more than that of 3T and 4T DRAM cell. Read Access Time tends to decrease as the supply voltage increases.

The most significant parameter for DRAM cell is retention time. 4T DRAM cell has the least retention time among the three cells. The retention time for 3T1D DRAM cell is significantly 
International Journal of VLSI design \& Communication Systems (VLSICS) Vol.5, No.4, August 2014

more than that of 4T and 3T DRAM cell. Retention time tends to decrease as the supply voltage increases.

The most significant parameter for DRAM cell is retention time. 4T DRAM cell has the least retention time among the three cells. The retention time for 3T1D DRAM cell is significantly more than that of 4T and 3T DRAM cell. Retention time tends to decrease as the supply voltage increases.

These results also show that average power consumption, read access time and write access time increase with temperature, while the retention time decreases with increase in temperature.

\section{REFERENCES}

[1] M. S. B. S. Shyam Akashe, "Analysis of power in 3T DRAM and 4T DRAM Cell design for different Technology," IEEE, vol. 12, no. 978-1-4673-4805-8, pp. 18-21, 2012.

[2] J. C. H. D. J. V. K. Wing k.luk, "A3-Transistor DRAM Cell with Gated Diode for enhanced Speed and Retention Time," Symposium on VLSI CircuitsDigest of Technical papers, vol. 06, no. 1-42440006-6, 2006 IEEE.

[3] j.-W. C. a. Y. C. Weijie Cheng, "Design of logic compatible Embedded DRAM using Gain Memory Cell," ISOCC, vol. 12, no. 978-1-4673-2990-3, pp. 196-199, 2012 IEEE.

[4] H. K. L. H. H. S. J. a. Y. R. Myungjae Lee, "Analysis of Dynamic Retention Characterstics of Nwl Scheme in High Density DRAM," IPFA, vol. 13, no. 978-1-4799-0480-8, pp. 641-644, 2013 IEEE.

[5] D. B. S. Z. Yong Sung Park, "Low Power High threshold LPDC decoder using non-refresh Embedded DRAM," JSSC, vol. 49, no. 0018-9200, pp. 1-12, 2014 IEEE.

[6] P.-T. H. a. W. H. Mu-Tien Chang, "A 65nm Low Power 2T1D Embedded DRAM With leakage Current Reduction," IEEE, vol. 07, no. 978-1-4224-1593-9, pp. 207-210, 2007.

[7] S. G. R. C. Nivard Asymerich, "Impact of Positive bias tempreature instability on 3T1D DRAM cells," Integration, the VLSI Journal, vol. 45, no. 2011 ELsevier, pp. 246-252, 2011.

[8] C. L. X. L. D. B. G.-Y. W. Kristen Lovin, "Emperical Performance Models for 3T1D Memories," IEEE, vol. 09, no. 978-1-4224-5028-2, pp. 398-403, 2009.

[9] E. Amat, "Strategies to enhance 3T1D DRAM cell variability robustness," Microelectronics Journal, no. 2013 Elsevier, pp. 1-6, 2013.

[10] Tutorial TANNER EDA LEDIT and TSPICE

[11] Thakre, Y. N. T. S. S., 2013. An effect of Process Variation On 3T1D DRAM. IJSER, 4(7), pp. 171178.

\section{AUTHORS}

Mr. Prateek Asthana is currently pursuing M.Tech in the field of advanced ECE with specialization in VLSI design. He has done his B.Tech from Amity University, Noida in the field of electronics and communication engineering in the year 2011. His research area includes VLSI design, low power VLSI design and Memories.

Mrs. Sangeeta Mangesh is assistant professor at JSS Academy of Technical Education, Noida. She is the guide and supervisor to the above research work. Her research area includes low power VLSI design, VLSI design and nanotechnology.
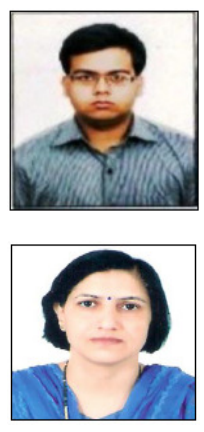